\title{
Variability of Solar UV Index in Nepal
}

\author{
Niranjan Prasad Sharma \\ Department of Engineering Science and Humanities, Pulchowk Campus \\ Institute of Engineering, Kathmandu, Nepal \\ Corresponding author: sharmaniranjanprasad@hotmail.com
}

Received: March 11, 2016 Revised: April 25, 2016 Accepted: May 10, 2016

\begin{abstract}
The paper presents the variability of solar UV index in main cities of Nepal. The latitude and longitude of the cities are $\left(27.72^{\circ} \mathrm{N}, 85.32^{\circ} \mathrm{E}\right),\left(28.22^{\circ} \mathrm{N}\right.$, $\left.83.32^{\circ} \mathrm{E}\right)$ and $\left(26.45^{\circ} \mathrm{N} 87.27^{\circ} \mathrm{E}\right)$ are located at an elevation of $1350 \mathrm{~m}, 800 \mathrm{~m}$ and $72 \mathrm{~m}$ respectively from the sea level. The NILU- UV irradiance meter of serial number $(135,137$ and 133) was used to record UV radiation on these stations. From the measurement and data analysis it was found that there were distinct diurnal, hourly mean and spring variations in the UV index. The UV index is primarily controlled by solar zenith angle for both the diurnal and seasonal variations. The highest values of hourly mean UV index was found at noon time in all seasons. Atmospheric parameters such as Solar Zenith angle (SZA), Cloud cover, aerosols and Ozone contribute to the daily fluctuations in the UV Index. The UV Index was found to be 8.72, 9.9 and 9.2 in June 9, in Kathmandu (KTM), Pokhara (PKR) and Biratnagar (BRT). While the UV Index (UVI) in September 27 was found to be 8.52, 8.18 and 9.36 in KTM, PKR and BRT respectively. Daily mean highest UV Index before monsoon at PKR was found to be 10.6 and 8.98 at day number 144 and 100 .
\end{abstract}

Key words: UV radiation, UV index, diurnal variation, cloud cover, exposure

\section{Introduction}

Solar UV radiation possesses strong biological effect on ecosystem. Sun is the ultimate source of energy and its emission includes visible spectrum and electromagnetic spectrum. UV radiation is a part of electromagnetic spectrum and is divided into three regions: UV-C (200-280 nm), UV-B $(280-315 \mathrm{~nm})$ and UV-A $(315-400 \mathrm{~nm})$. Atmospheric oxygen and ozone absorbs all UV-C radiation and prevent it from reaching the troposphere and the earth's surface. A small part of UV-B radiation can reach the earth's surface. Relatively a greater amount of UV-A radiation can reach the earth's surface.

Solar ultraviolet (UV) radiation reaching the earth's surface has a wide range of effects on humans, aquatic and terrestrial ecosystems $[1,12]$. For humans, exposure to UV radiation has been linked to sunburn, skin cancer, corneal damage and cataracts [4]. A beneficial effect of UV radiation is the photochemical production of vitamin D in the skin [9]. Vitamin D is essential for the formation of bones [7] and may also protect from internal cancers [6]. On one hand, reflections from snow covered surfaces and the long hours of sunshine during summer months can lead to considerable UV exposure [2]. Stratospheric ozone content influences solar UV irradiance received at the Earth's 
surface in very different amounts through the UV range; e.g. the effective absorption cross-section is 20 times less at $340 \mathrm{~nm}$ than at $300 \mathrm{~nm}$ [11]. As a consequence, ground UV-B irradiance is only a fraction as low as 5\%, of the whole ultraviolet irradiance. Total UV irradiance shows daily and yearly cycles that strongly depend on the geographic latitude and on other local conditions such, as altitude above the mean sea level, cloudiness, ground albedo, etc. The UV climatology at a specific site depends primarily on the time of day and day of the year secondly on cloudiness and thereafter on the type and amount of aerosols [5].

UV radiation shows a diurnal and annual cycle which depends on the solar elevation defined by the geographical location and time. Atmospheric ozone and aerosol scattering are the other important parameters determining the global solar irradiance. In general, the higher the UV index more will be its damaging effect to the human skin. This paper documents the level of UV index in different parts of Nepal. The main focus of this paper is presenting the diurnal, hourly mean summer and spring variability of solar UV index for 2009 .

\section{Methodology}

\subsection{Instrument Description and Locations}

Kathmandu $\left(27.72^{\circ} \mathrm{N}, 85.32^{\circ} \mathrm{E}\right)$, Pokhara $\left(26.45^{\circ} \mathrm{N} 87.27^{\circ} \mathrm{E}\right)$ and Biratnagar $\left(26.45^{\circ} \mathrm{N} 87.27^{\circ} \mathrm{E}\right)$ and are located at an elevation of $1350 \mathrm{~m}, 800 \mathrm{~m}$, and $72 \mathrm{~m}$ respectively. The instruments used during measurement were NILU-UV irradiance meters. The instrument has a Teflon diffuser designed to obtain a good cosine response for the angular sensitivity. After passing the diffuser, the incoming radiation is passed through band pass filters with a very low out-of-band transmittance. The filtered light is converted into electric currents by photo detectors, one for each channel. The photo detector consists of a conduction band and valence band. Photons move electrons from the valence band on to the conduction band and forms currents $\left(\mathrm{C}_{\mathrm{i}}\right)$. The currents are subsequently amplified, digitized and converted to absolute irradiances for each channel. The NILU-UV is a six channel radiometer designed to measure hemispherical irradiances on a flat surface. UV doses with various action spectra and total ozone column amounts can be derived from the measured irradiance by using a technique described by [3]. The NILU-UV comprises of 5 different channels with center wavelengths at $305 \mathrm{~nm}, 313 \mathrm{~nm}, 320 \mathrm{~nm}, 340 \mathrm{~nm}$ and $380 \mathrm{~nm}$.

\section{Results and Discussion}

Diurnal, Hourly mean, summer and pre-monsoon variability of solar UV index at three different sites of Nepal for 2009 was analyzed in this paper. Diurnal variation of UV Index for June 9, September 27, and November 1 at Kathmandu, Pokhara and Biratnagar has also been reported. These UV Index were found to be 8.72, 9.9 and 9.2 in June 9 in KTM, PKR and BRT at 6.75 UT, 6.37 UT and 5.9 UT respectively as shown in Fig. 1. 


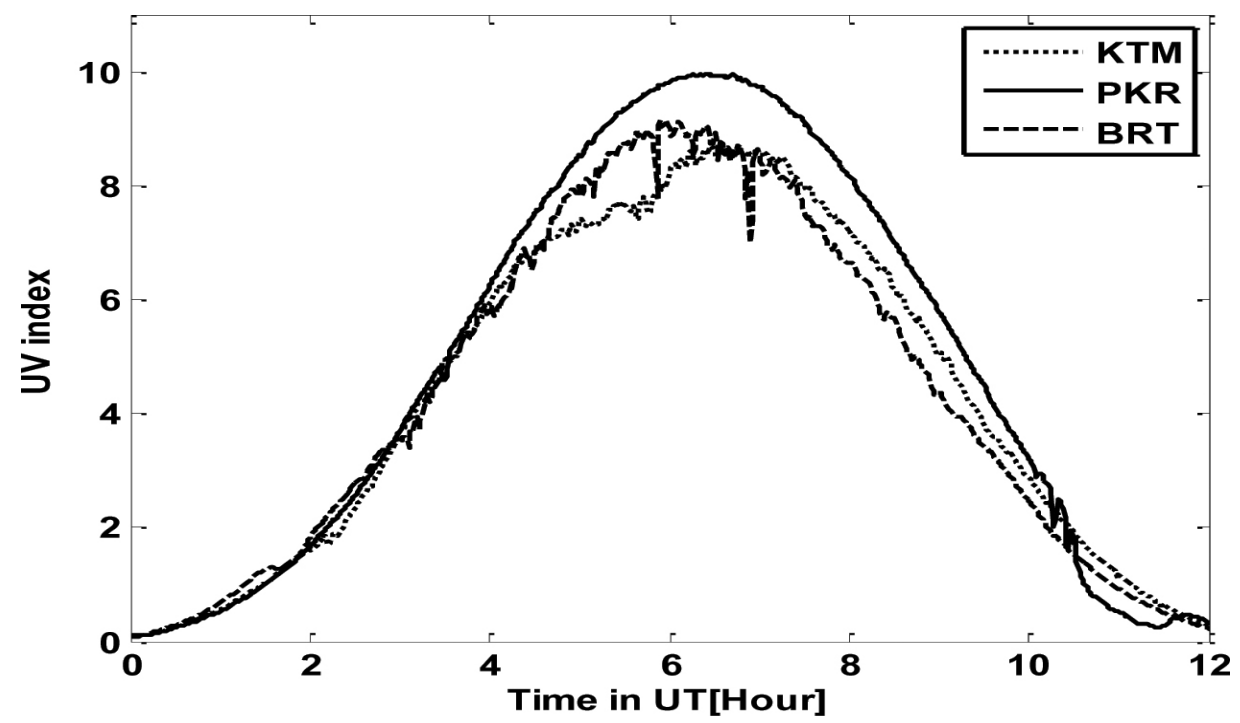

Fig. 1: Diurnal Variation of Solar UV Index in June 9, 2009 at Kathmandu, Pokhara and Biratnagar

The UV index in September 27 were found to be 8.52, 8.18 and 9.36 at 6.22 UT, 6.23 UT and 5.85 UT in KTM, PKR and BRT respectively as shown in Fig. 2.

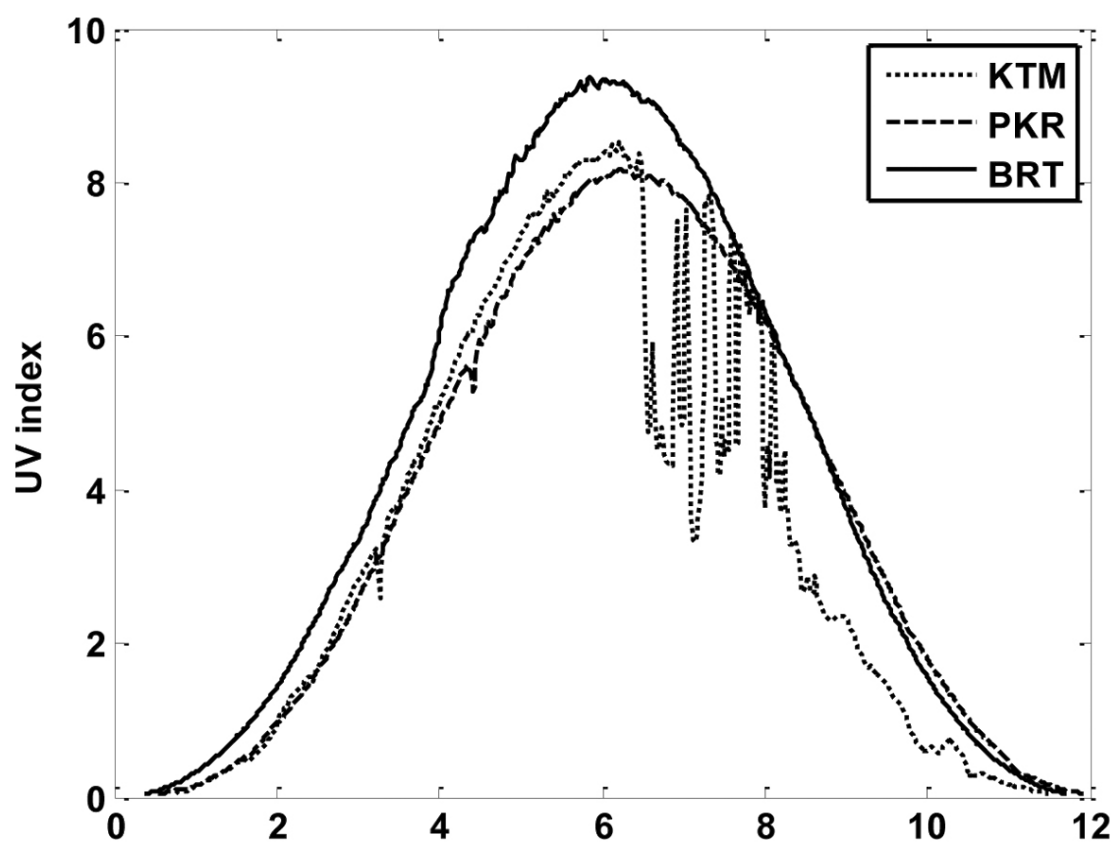

Fig. 2: Diurnal Variation of Solar UV Index in September, 27, 2009 at Kathmandu, Pokhara and Biratnagar 


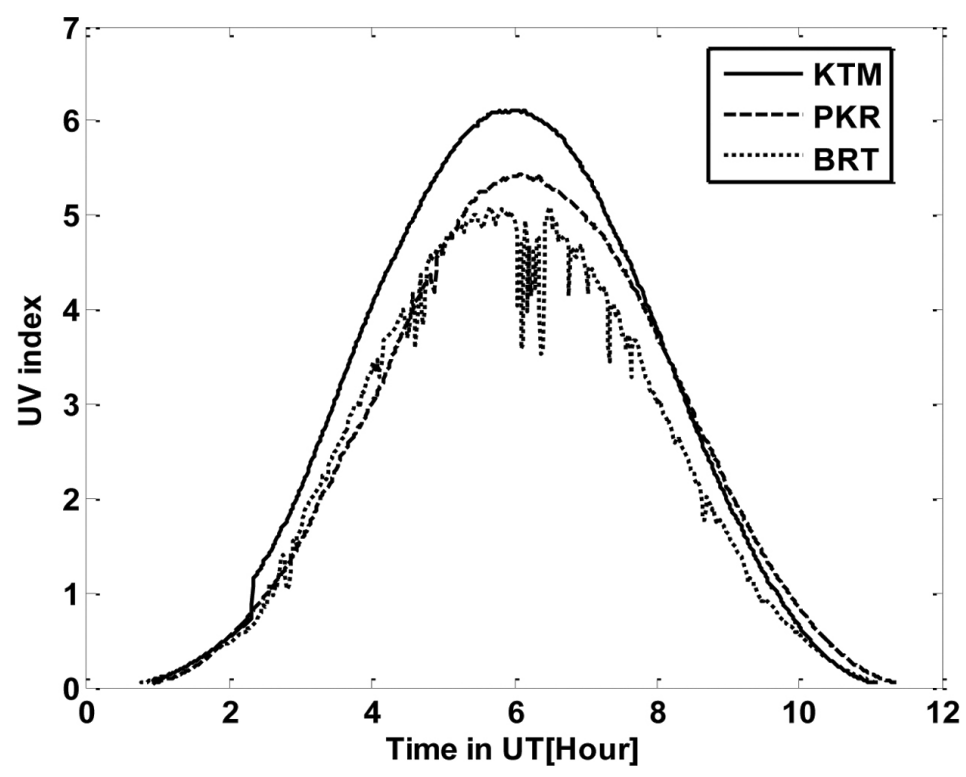

Fig. 3: Diurnal Variation of Solar UV Index in November 1, 2009 at Kathmandu, Pokhara and Biratnagar

The UV Index was found to be 6.1 at 5.85 UT in KTM, 5.4 at 6.05 UT in PKR and 5.09 at 6.5 UT in BRT for November 1 as shown in Fig. 3. Similar result was found by [8] which states that the variation of solar UV Index in Estonia for March 29 (2000), September 13 (1998) and September 8 (1999) are 2.51, 3.60 and 3.58 respectively. Data analysis showed that, clouds sometimes enhanced the solar UV radiation while in other cases it reduced the solar UV radiation reaching the earth's surface.

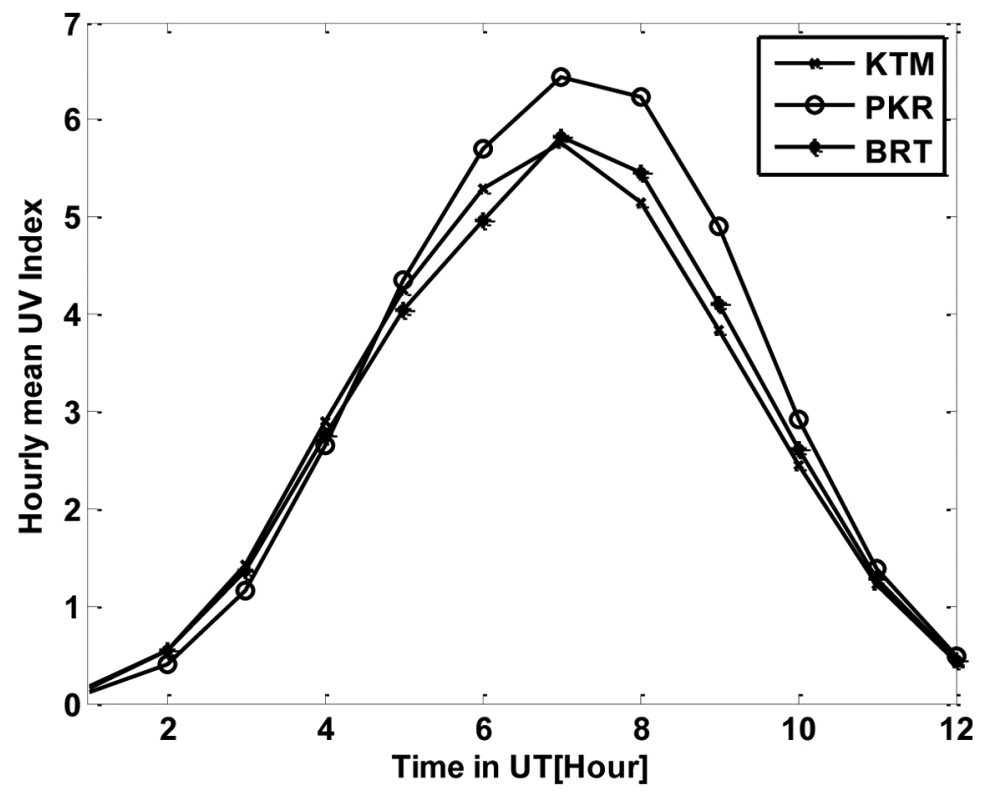

Fig. 4: Hourly mean UV Index in summer 2009, at Kathmandu, Pokhara and Biratnagar 
Hourly mean UV Index in summer was found to be 5.75, 6.43 and 5.83 in 7.00 UT at KTM, PKR and BRT respectively as shown in Fig. 4. These high values of UV Index for all seasons at noon hour time is due to high solar elevation. It was also observed by [10] according to which the hourly mean UV Index observed at 1 P.M in Hongkong ranges from $0.08-13.79$.

Attenuation of solar UV radiation is different for different season. And the seasonal variation of solar UV index is due to the difference in solar zenith angle. Furthermore the highest daily mean UV Index before monsoon were found to be 10.6 at day number 144 and 8.98 at day number 100 at PKR as shown in Fig. 5. The highest UV index in PKR before monsoon is due to less effect of clouds and aerosol and low solar Zenith angle.

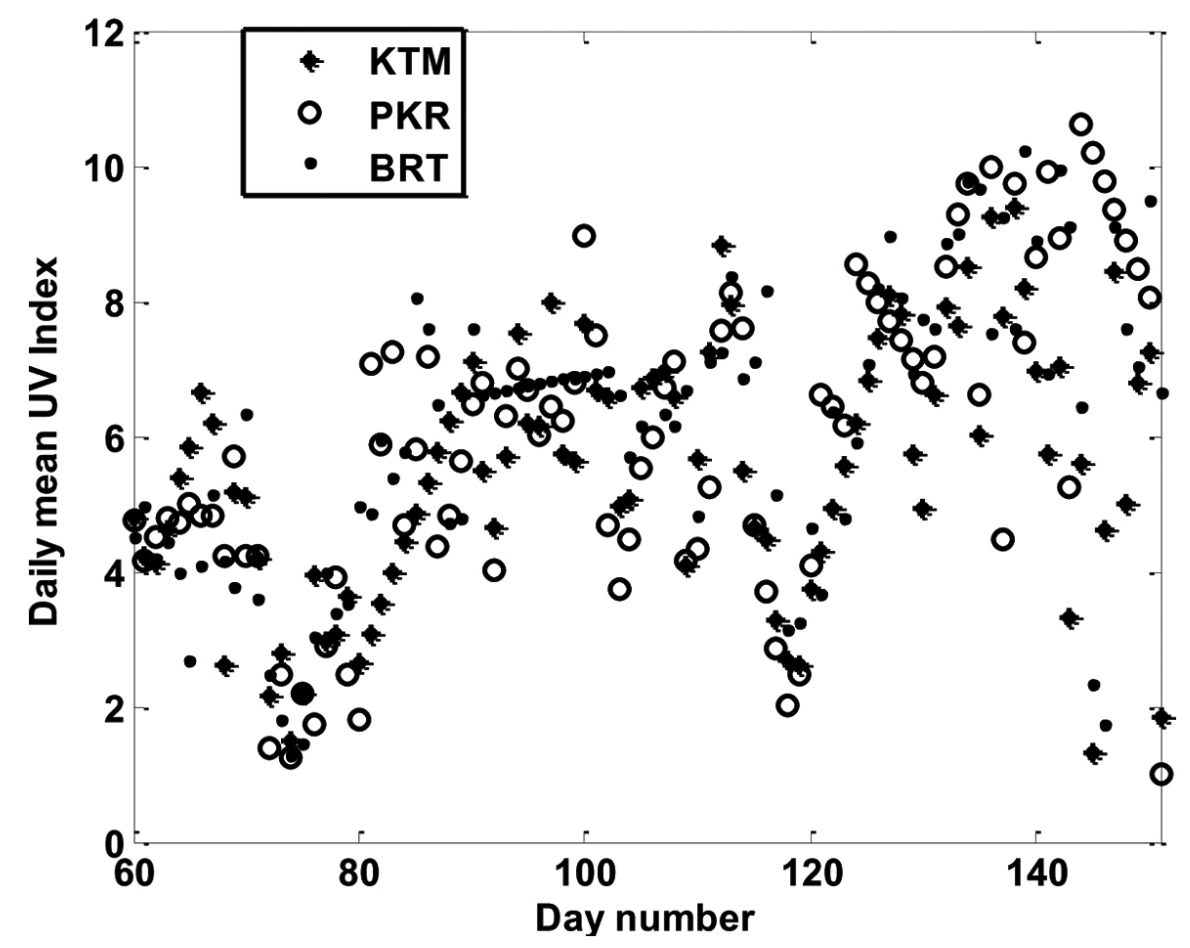

Fig. 5: Variations of Noon hour UV Index in pre-monsoon, 2009 at Kathmandu, Pokhara and Biratnagar

\section{Conclusion}

In June 9, the UV Index at Pokhara was found to be higher than that of Kathmandu and Biratnagar. Similarly in September 27, the UV Index at Biratnagar was found to be higher whereas in November 1, UV index at Kathmandu was higher. Meanwhile the hourly mean summer and pre-monsoon UV index was higher in PKR compared to other sites. We also found that the diurnal variability of solar UV index is mainly due to different factors such as, solar zenith angle, ozone, cloud cover and aerosols present in the atmosphere. Finally the overall data analysis showed that there is UV index variability in the measurement sites of Nepal. 


\section{Acknowledgement}

We are grateful to Solar Radiation and Aerosol Project in the Himalaya Region (SAHR), Institute of Engineering, Department of Engineering Science and Humanities, for providing necessary data.

\section{References}

[1] Arctic Climate Impact Assessment (ACIA) (2006), Cambridge University Press, New York, USA, $1042 \mathrm{pp}$

[2] Cockell CS, Scherer K, Horneck G, Rettberg P, Facius R, Gugg-Helminger A, Driscoll C, and Lee P (2001), Exposure of Arctic field scientists to ultraviolet radiation evaluated using personal dosimeters. Photochem. Photobiol., 74(4): 570-578.

[3] Dahlback A (1996), Measurements of biologically effective UV doses, total ozone abundances, and cloud effects with multi-channel, moderate bandwidth filter instruments. Appl. Opt., 35: 6514-6521.

[4] De Gruijl, FR, Longstreth J, Norval M, Cullen AP, Slaper H, Kripke ML, Takizawag Y and van der leun JC (2003), Health effects from stratospheric ozone depletion and interactions with climate change. Photochem. Photobiol., Sci., 2: 16-28.

[5] Foyo-Moreno I, Alados I, Olmo FJ and Alados(2003), The influence of cloudiness on UV global irradiance (295-385 nm). Agr. Forest Meteorol., 120: 101-111.

[6] Grant, WB (2002), An estimate of premature cancer mortality in the US due to inadequate doses of solar ultraviolet-B radiation. Cancer, 94(6): 1867-1875.

[7] Holick M (1996), Vitamin D and Bone Health. J. Nutr., 126: 1159S-1164S

[8] Eerme K, Veismann U and Koppel R (2002), Variations of erythemal ultraviolet irradiance and dose at Tartu/Toravere, Estonia. Climate Research, 22: 245-253

[9] Lehmann B (2005), The vitamin D3 pathway in human skin and its role for regulation of biological processes. Photochen Photobiol., 81(6): 1246-1251

[10] Leung YK, Cheng YY and Ginn EWL (2004), Ultraviolet Index in HongKong. HongKong Observatory, Technical Note (local) No. 80.

[11] Molina LT and Molina MJ (1986), Absolute absorption cross section of ozone in the 185 to 350 nm wavelength range. J. Geophys. Res., 95: 14 501-14 508

[12] United Nations Environmental Program (UNEP) (2003), Environmental effects of ozone depletion and its interactions with climate change: 2002 assessment; executive summary. Photochem. Photobiol. Sci., 2: 1-4 